\title{
A review of standards for hybrid CPV-thermal systems
}

\author{
M. Vivar ${ }^{\mathrm{a}, *}$, M. Clarke $^{\mathrm{b}}$, J. Pye ${ }^{\mathrm{c}}$, V. Everett $^{\mathrm{a}}$ \\ a Centre for Sustainable Energy Systems, Australian National University, Canberra, Australia \\ ${ }^{\mathrm{b}}$ Institute for Thermodynamics and Energy Conversion, Vienna University of Technology, Austria \\ c College of Engineering, Australian National University, Canberra, Australia
}

\section{A R T I C L E I N F O}

\section{Article history:}

Received 28 July 2011

Accepted 22 August 2011

Available online 15 September 2011

\section{Keywords:}

Hybrid

Concentrator

Active cooling

Reliability

Photovoltaic

Thermal

\begin{abstract}
A B S T R A C T
A comprehensive review on standards for actively-cooled CPV and CPV-T systems is presented. Since these systems lack specific standardisation, this review concludes that the current standards, including the photovoltaic IEEE 1513 and IEC 62108, and the solar thermal EN-12975-2:2006 and ISO 9806-2:1995, are insufficient for qualifying these types of actively-cooled concentrator systems. Additional test specifications for adapting the IEC 62108 and EN-12975-2:2006 standards for actively-cooled CPV and CPV-T systems have been proposed.
\end{abstract}

(C) 2011 Elsevier Ltd. All rights reserved.

\section{Contents}

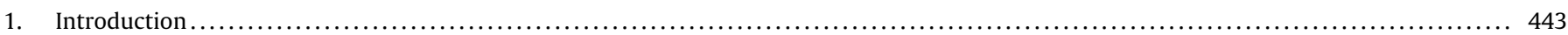

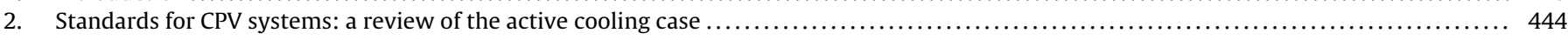

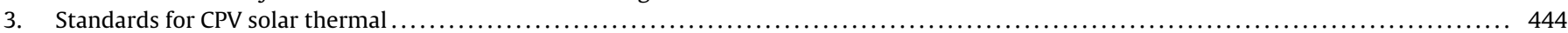

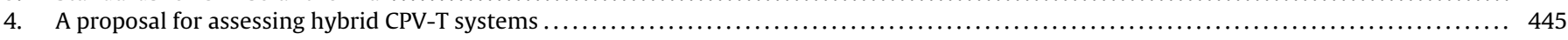

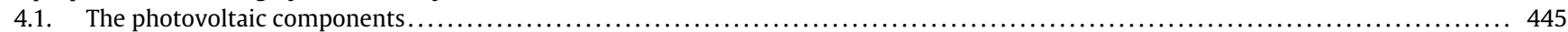

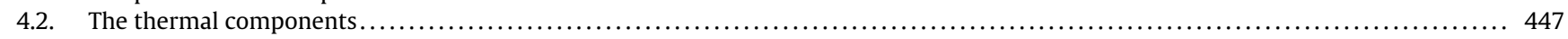

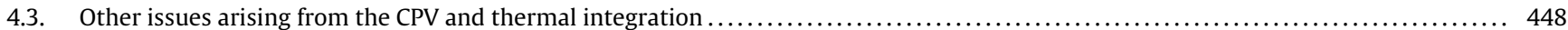

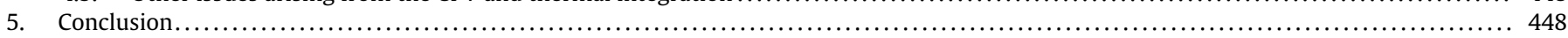

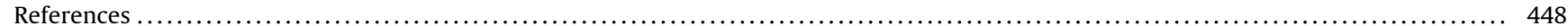

\section{Introduction}

System and component reliability are widely recognised as critical aspects of new electronic components and devices. For each component, qualification tests and other assessment procedures are usually specified in international standards, such as the IEC (International Electrotechnical Commission) or the ASTM (American Society for Testing and Materials). Similarly, qualification tests for standard or representative systems comprising these tested components are also formally specified.

When developing a new technology without associated standards, particularly at a system level, new tests must be designed in order to determine the reliability and durability of the new systems. These assessment tests are usually based on previous standards,

\footnotetext{
* Corresponding author.

E-mail address: marta.vivar@anu.edu.au (M. Vivar).
}

with modifications and adaptations designed to address the specific additional requirements of the new device. A case in point is the hybrid concentrator photovoltaic-thermal (CPV-T) system, which lacks specific standards for qualification and reliability assessment. In this case, where no official standards are available to qualify this type of system, the relevant photovoltaic thermal standards must be reviewed in order to design suitable test procedures to assess the new technology.

Hybrid CPV-T receivers are neither purely photovoltaic, nor purely thermal; so special requirements for tests associated with the active cooling systems will arise when conducting the approved test sequences for solar CPV systems, such as those specified by the IEC 62108 standard. In order to verify the suitability of the IEC 62108 standard for determining CPV-T receiver reliability, the IEC 62108 tests have been analysed for applicability to actively-cooled systems. Extensions of the standard tests, and additional new tests, or modifications of existing tests where applicable, will be presented. 
Concurrently with the CPV tests, the solar thermal component of the CPV-T system must undergo a separate range of specified tests, which usually incorporates the current local standards for these applications. For this reason, standards covering domestic hot water applications and concentrator solar thermal collectors will be reviewed and incorporated in the proposed CPV-T standards in order for the hybrid system to comply with standards required for a purely thermal system.

This paper will present a combined sequence of tests, incorporating the IEC 62108 standards, under development at ANU that is designed to qualify the photovoltaic and thermal performance and reliability of an actively-cooled hybrid CPV-T system. An evaluation of the currently available standards and their considerations will be presented, along with an initial assessment of the most appropriate tests, including additional test requirements, for hybrid systems in order to guarantee their long-term electrical and thermal performance.

\section{Standards for CPV systems: a review of the active cooling case}

The lack of standards for CPV system qualification is not a new issue; it has been thoroughly analysed by Muñoz et al. [1] in their review on the state-of-the-art of CPV standardisation. Currently, there are only two relevant standards: the IEEE 1513 [2] and the IEC 62018 [3], with both constructed solely for CPV receivers. However, these standards are limited to three different technologies in the case of the IEEE 1513, and five technologies in the case of IEC 62108. New CPV technologies are constantly emerging, and the standards are not always appropriate for assessing the performance and reliability of the new systems.

In the case of hybrid concentrator systems that include photovoltaic as well as thermal output, one possible option is to follow the current standards as a template for defining a set of tests in order to establish the durability of the system. The main issue with this approach is the question of how to determine and analyse the suitability of the proposed tests for actively-cooled CPV and CPV-T systems. Consideration of the IEEE 1513 standard, 'IEEE Recommended Practice for Qualification of Concentrator Photovoltaic (PV) Receiver Sections and Modules', leads to the conclusion that this standard includes no special consideration for active-cooled systems. This is despite the standard including linear focus systems, which can operate with active or passive cooling, as one of the specifically described technologies.

In contrast to the IEEE 1513 standard, the new IEC 62108 standard, 'Concentrator Photovoltaic (CPV) Modules and Assemblies-Design Qualification and Type Approval', includes five distinct types of CPV systems. Of these five systems, only one, the point-focus dish PV concentrator incorporates, active cooling. Thus, it would be expected that the standard would cover this issue in detail. However, a detailed review of the standard leads to the conclusion that the lack of specifications and details leaves a very broad scope in which to interpret and conduct the different tests.

As an example, there are several tests that do not provide any reference to active cooling, such as dark I-V measurement, ground path continuity, thermal cycling test, damp heat test, humidity freeze test, bypass/blocking diode thermal test, and off-axis beam damage test. For some of these tests, such as for example the dark I-V measurement, the effect of active cooling and whether or not it is operational, would be unlikely to affect the performance. For some other tests, however, the result with and without active cooling can be dramatically different. Consider the thermal cycling test, where the standard specifies the injection of electrical cycles. In this case, passively-cooled systems have a distinct advantage over actively-cooled systems if the coolant is not flowing.
As matters presently stand, when the chamber is at a uniform temperature and current is injected into the receiver, the passive cooling system commences to function, since there is a heat focus on the cells that will be spread into the heat sink. In this case, the passively-cooled system has all the thermal mass and thermally conductive pathways required for conducting the heat, so the passively-cooled receiver will operate in a similar state to that of real operating conditions. In contrast, the actively-cooled system will be at a disadvantage if the coolant is not flowing. In this situation, the receiver will be subject to much higher localised thermal stresses, since heat conduction to the surroundings will be neither appropriate, nor realistic. In this case, the test will be unrepresentatively harsh for the actively-cooled receiver, and the results will not be useful, since the test will not be reproducing representative operating conditions. For this situation, the implementation of standards tests requires careful review of the specifications, and consideration of the test procedure limitations when using actively-cooled $\mathrm{CPV}$ receivers.

There are additional tests that include some considerations that are relevant to actively-cooled systems in the IEC 62108 standard. These include the outdoor side-by-side I-V measurement, the electrical insulation test, the ultraviolet conditioning test, and the outdoor exposure test. Unfortunately, the test descriptions are not always very clear, and the conditions they impose are unusually broad. For example, the ultraviolet conditioning and outdoor exposure test descriptions specify only that 'If the system requires active cooling, the cooling system should be operated during the test'. Similarly, for the outdoor side-by-side I-V measurement the test description specifies that 'If coolant is employed, monitor coolant flow rate and inlet/outlet temperatures. The coolant flow rate should not change by more than $2 \%$, and the temperature should not change by more than $1{ }^{\circ} \mathrm{C}$ in any 5-min period'. However, the standard test description does not address the flow rate requirements of the system. The test results will be very different when using a high flow rate to that of a low flow rate, where large temperature gradients exist within the receiver. Finally, for the electrical insulation tests, which includes both dry and wet tests, the specified condition is that 'Designs that use a cooling medium should have the cooling medium present during the test, but the cooling medium circulation is not required'. The specification does not answer the question as to why the cooling medium circulation is not required.

From this review, it can be concluded that the IEEE 1513 standard is inadequate for testing actively-cooled CPV or CPV-T modules. Furthermore, although the IEC 62108 standard considers one particular actively-cooled system as one of the analysed technologies, the associated test specification is not clear and lacks procedural detail and analysis of the limitations that arise when conducting tests for other actively-cooled systems.

\section{Standards for CPV solar thermal}

Hybrid concentrator photovoltaic-thermal systems produce electricity as well as low-grade heat for hot water domestic applications. As solar thermal systems, they should comply with the current official standards in order to guarantee fully functional operation and durability of the thermal part. The most common standards used for solar thermal systems are the European Standard EN-12975-2:2006 'Thermal Solar Systems and Components. Solar Collectors-Part 2: Test methods' developed by AEN/CTN 94 committee [4] and the ISO 9806-2:1995, 'Test Methods for Solar Collectors-Part 2: Qualification test procedure' [5]. Both of these standards specify the tests that a solar collector should pass in order to guarantee their durability. None of these standards mention any special considerations for hybrid photovoltaic-thermal systems. The ISO 9806-2:1995 even states that it does not apply to tracking 
concentrator collectors. On the other hand, the EN-12975-2:2006 includes solar concentrator collectors, from static concentrators such as CPC's (compound parabolic collectors), to high concentration systems with two-axis tracking. However, this standard does not then proceed to specify any special requirements for tracking or non-tracking concentrator collectors.

The different tests included in these standards have been reviewed in order to determine their suitability for solar CPV and CPV-T systems; not only for solar concentrator thermal. The list of reliability tests for solar collectors included in the EN-129752:2006, which are basically the same as for the ISO 9806-2:1995, are:

- Internal pressure.

- High temperature resistance.

- Exposure.

- External thermal shock.

- Internal thermal shock.

- Rain penetration.

- Freezing resistance.

- Mechanical load.

- Impact resistance.

- Final inspection.

From the above set of tests, there are some that would not be affected by the fact that the collector includes photovoltaic solar cells. These include the internal pressure test $(15 \mathrm{~min}$ at 1.5 times the maximum pressure of the system, with ambient temperature between $5^{\circ} \mathrm{C}$ and $30^{\circ} \mathrm{C}$ ); the rain penetration test ( $4 \mathrm{~h}$ of water spray, water temperature $<30^{\circ} \mathrm{C}$, with flow rate $>0.05 \mathrm{~kg} / \mathrm{s} \mathrm{m}^{2}$ ); the freezing resistance (if the fluid does not include anti-freezer); the mechanical load (positive pressure test, negative pressure test of fixings, negative pressure test of mountings); and the impact resistance test (hail or steel balls, optional). However, there is another group of tests related to high solar irradiance exposure with no liquid circulation that is conducted in order to determine the high temperature resistance of the materials, which could be critical when photovoltaic solar cells are included. These tests include the high temperature resistance test, the exposure test, and the external and internal thermal shock tests.

Consider the high temperature resistance test, which checks whether the collector is able to withstand high levels of solar irradiance without materials failures, such as glass breakage, collapse of plastic cover, melted plastic connectors, and other materials durability properties. The test conditions are: solar irradiance higher than $1000 \mathrm{~W} / \mathrm{m}^{2}$ in the plane of the solar collector, ambient temperature between $20^{\circ} \mathrm{C}$ and $40^{\circ} \mathrm{C}$, wind speed less than $1 \mathrm{~m} / \mathrm{s}$, and no fluid in the absorber. For hybrid solar photovoltaic-thermal systems, this test can not be conducted as specified since the solar cells and their interconnections, such as soldering points, could be damaged. The same issue applies to the exposure test, that requires 30 days with a minimum irradiation of $14 \mathrm{MJ} / \mathrm{m}^{2}$ per day and $30 \mathrm{~h}$ of at least $850 \mathrm{~W} / \mathrm{m}^{2}$, with ambient temperature higher than $10^{\circ} \mathrm{C}$ and no fluid inside the absorber. This latter requirement, that of no fluid in the absorber, can seriously affect the photovoltaic part of the actively-cooled system, with the cells under concentrated light and requiring cooling to avoid damage.

With respect to the external and internal thermal shock tests, both require the collector to be initially exposed at least for $1 \mathrm{~h}$ at high irradiance $\left(>850 \mathrm{~W} / \mathrm{m}^{2}\right)$, again with no fluid inside the receiver. For the external thermal shock, water is then sprayed for $15 \mathrm{~min}$, with subsequent checks for possible failures. For the internal thermal shock test, the fluid is circulated after the initial exposure until the absorber temperature drops below $50^{\circ} \mathrm{C}$. Both tests are in serious conflict with the design requirements of the photovoltaic part of the system, since under these test conditions

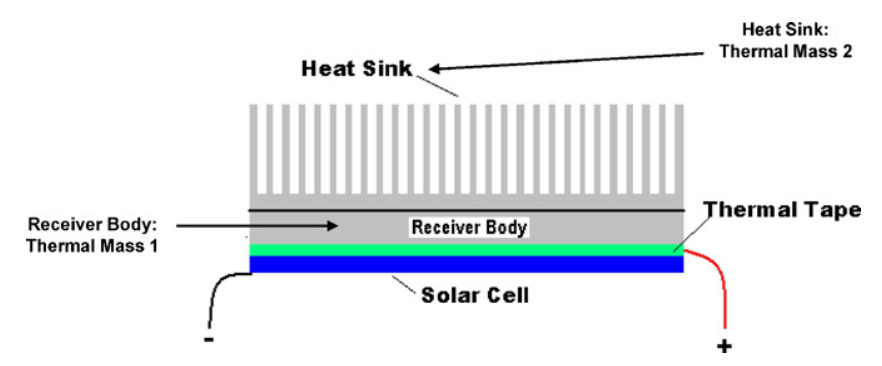

Fig. 1. Example of a passively-cooled receiver with attached heat sink.

the absorber could reach very high temperatures and lead to failure of the cells or electrical circuitry.

These solar thermal tests must be modified for to accommodate materials and design properties of hybrid CPV and CPV-T receivers for those test cases which could reach high absorber temperatures that could damage the solar cells and their interconnections. At the very least, these modifications include fluid circulation, or by establishing a maximum acceptable receiver temperature during the test procedure.

\section{A proposal for assessing hybrid CPV-T systems}

When assessing hybrid systems, the photovoltaic components as well as the thermal components must be tested. Therefore, an initial set of tests based on these two inter-related requirements are proposed.

\subsection{The photovoltaic components}

When determining the test conditions for the photovoltaic components, it is important to understand the major differences between a passively-cooled receiver and an actively-cooled receiver with respect to their thermal mass, heat transfer properties and pathways, and internal thermal gradients within the receivers, as shown descriptively in Figs. 1 and 2. In principle, while it is possible to create similar testing conditions between the two designs, it is necessary to consider two issues and incorporate two principles:

(1) Test conditions should be derived in such a way that the tests are fair and scientifically valid, but these conditions should not be specified in such a way that the true performance differences, in both reliability and power output, are masked or eliminated. There are certain intrinsic differences between receiver designs, which are in fact true differences, and should be allowed to remain so.

(2) Additional and unnecessary complexity in the set-up and conduct of validation tests should be avoided as far as possible.

With regards to the latter point, many of the current discussions in this field seem to focus on whether or not to include the

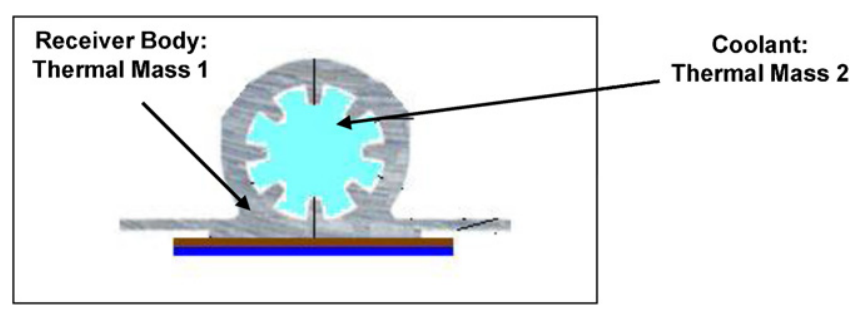

Fig. 2. Example of an actively-cooled receiver. 
coolant within the receiver, and whether or not to circulate the coolant as part of a particular test. It is suggested that for any test which requires the circulation of coolant, it is also a requirement that the outlet temperature of the coolant is specified. If the coolant temperature is not specified, it is possible to unintentionally introduce more uncertainty and differences between the tests than the uncertainty that is removed by the addition of a coolant flow rate requirement.

Recommendation 1: That any certification of a CPV or CPV-T actively-cooled receiver should be performed for a specified maximum outlet temperature (MOT). The specification of the MOT is to be made by the manufacturer for the particular receiver design. Therefore, a certified receiver design would be certified for a MOT, which would be specified on the certification label applied to the receiver. This would allow manufacturers a degree of flexibility in design and testing, but would also protect the consumer by informing them that this particular receiver was certified at a particular MOT, and that exceeding this temperature runs an increased risk of failure and possible voidance of warranty.

Recommendation 2: That a maximum delta $T$ from inlet to outlet of an actively-cooled CPV-T receiver is specified. The delta $T$ would be incorporated into any certification label. The purpose of this is to place an operational limit on the thermal gradient along the receiver length, which the manufacturer would certify the module or system. This would mean that systems could be installed throughout the world with confidence because they have been tested for appropriate temperature conditions. In addition, if the manufacturer or installer wishes to use higher flow rates, which would reduce the operational delta $T$ to below the maximum certified delta $T$ then the installer and consumer can be reassured that the real-life operating conditions to which the receiver is exposed introduce less stress than those used in the certification process.

To summarize, it is proposed that a CPV or CPV-T certified actively-cooled module be labeled with its certification number, such as IEC62108, and the label should also include the specified MOT and Max delta $T_{\text {inlet-outlet }}$.

Under the scenario described above, the IEC62108 test standards could be relatively easily adapted to cover all requirements of the CPV-T systems. A proposal has been prepared for adapting the existing IEC62108 tests to accommodate actively-cooled systems. This proposal specifies detailed test procedures and test conditions, such as when active cooling must be used and at what temperature, and at which maximum outlet temperature as determined by the flow rate. In general, when active cooling is used, one of the main issues is the determination of the maximum outlet temperature, which directly determines the flow rate. This present proposal uses a flow rate that is equivalent to the real flow rate used in a full-sized system. This means using a flow rate that produces a temperature drop across the receiver, and temperature profiles within a receiver, that are similar to real operating conditions.

Consider the case of a full length linear concentrator system with an operating flow rate of $250 \mathrm{ml} / \mathrm{s}$. An equivalent flow rate for a smaller test sample should be calculated, since the full flow rate can be too large for a small sample, resulting in increased measured performance of the receiver, which would not be valid under normal real operating conditions. On the other hand, specific flow rates can be a feature of actively-cooled designs, where turbulent flow is required for effective cooling. Under these circumstances, it is important to allow the test standards the latitude to specify coolant flow rates that reflect design performance as well as realistic operating conditions. With regard to the question of when to use active cooling during the tests, the proposal suggests coolant flow rates calculated to make the experiment as real as possible. An additional consideration is to put the actively-cooled receiver in the same operating conditions as passively-cooled receivers. For example, the presently proposed tests include using active cooling during the thermal cycling test when the electrical cycles are on, in order to establish equivalent operating conditions with passive cooling systems.

With respect to some specific tests, such as the electrical insulation test, it can be seen that the addition of coolant medium to the $\mathrm{CPV}-\mathrm{T}$ receiver increases the number of conduction pathways, and hence increases the likelihood of failure for this test. At the receiver level, it follows that the coolant should be present in the receiver, but that for this test, no circulation would be required. On a system level, where the piping and pumps are included, the presence of coolant certainly poses additional risk, and in these circumstances, it should be tested under circulation.

When analysing some of the most critical tests, such as the thermal cycling test, the presence of a coolant, and the coolant flow-rate, is not considered in the current standard. When considering the coolant flow, it would be reasonable to consider it to be strongly correlated with the standards requirement of a minimum of $1.25 \mathrm{I}_{\mathrm{sc}}$ current injection. As the standard currently reads, the reason for including current injection is to create a thermal gradient between CPV cells and the receiver itself across the thermal interface. However, the standard specifies that $1.25 \mathrm{I}_{\mathrm{sc}}$ is the minimum, that the thermal gradients should be determined using commercial software, and that the current injection should be adjusted accordingly. Following this line, it could be argued to exclude the coolant from the receiver and to adjust the current injection to account for the lower thermal mass.

If the coolant is present, whether it is circulating or not, it will increase the thermal mass of the system. However, this should have a relatively small effect, if any, on the thermal gradient across the thermal interface. On the other hand, the presence of coolant would affect the time at which the interface is exposed to this thermal gradient, and it would also unnecessarily add extra complexity to the test. For these reasons, it was decided to utilise the first option; that of excluding the coolant and adjusting the current injection to accommodate for lower thermal mass.

Finally, when analysing the off-axis beam damage test, the existing standard provides a special case procedure in which a system can utilise a fail-safe mechanism. Therefore, demonstration of a walk-off test is not required. However, this particular test could be slightly expanded in order to consider two failure modes:

1. A so-called "Grid-failure" test in which both the tracking capability and the pumping of the coolant is lost. To pass this test, the receiver, module, or assembly, depending on the type of system, must either: (a) pass the $3 \mathrm{~h}$ walk-off specified in the existing standard; or (b) trigger a fail-safe mechanism to manage misalignment issues.

2. A complete loss of coolant event, such as in the case of a ruptured pipe or fitting. In this case, the receiver, module, or assembly would be subjected to a sudden loss of coolant and should, again: (a) pass the $3 \mathrm{~h}$ walk-off specified in the existing standard, or (b) trigger a fail-safe mechanism to manage misalignment issues.

Although these two tests share some common features, which lead to test redundancies, it is important that any fail-safe system demonstrates the ability to handle both types of failures. It is also important that a 3-h walk off test does not, through boiling of the coolant, pressurize the receiver to the extent that it ruptures. Such a rupture event would be extremely dangerous were anyone to be near the system at this time.

To summarize all the variations, Table 1 shows the update proposed for the use of the IEC 62108 standard for actively-cooled systems. 
Table 1

Variations proposed to the IEC 62108 for active cooled module qualification.

\begin{tabular}{|c|c|c|c|}
\hline Tests\# & Test title & Test condition & $\begin{array}{l}\text { Variation proposed for active cooled } \\
\text { systems }\end{array}$ \\
\hline 10.2.2.1 & Electrical performance & $\begin{array}{l}\text { Outdoor side-by-side I-V with DNI }>700 \mathrm{~W} / \mathrm{m}^{2} \text {, } \\
\text { wind speed }<6 \mathrm{~m} / \mathrm{s} \text {, clear sky. } \\
\text { Dark I-V as a diagnostic means to measure } \\
\text { resistance, at least } 10 \text { points from } 0.9 \text { to } 1.6 \text { Isc }\end{array}$ & $\begin{array}{l}\text { Assemblies: } \\
\text { Cooling system working. } \\
\text { Flow rate calculated for a small sample } \\
\text { as equivalent to full size module } \\
\text { (equivalent temperature drop across } \\
\text { the receiver). } \\
\text { Max outlet temperature (MOT) } \\
\text { Max delta } T \text { across the receiver }\end{array}$ \\
\hline 10.4 .2 & Electrical insulation test & $\begin{array}{l}\text { At ambient temperature, } 25 \pm 10^{\circ} \mathrm{C} \text { and } \mathrm{RH} \\
<75 \% \text {, apply } 2 * V \text { sys }+1000 \mathrm{~V} \text { for } 2 \mathrm{~min} \text { (hi-pot). } \\
\text { Measure } R \text { at } 500 \mathrm{~V} \text {. } \\
\text { Coolant present, no circulation required }\end{array}$ & $\begin{array}{l}\text { Receiver or module: } \\
\text { Coolant present, no circulation } \\
\text { Assemblies: } \\
\text { Max outlet temperature (MOT) } \\
\text { Use same flow rate from Test } 10.2 .2 .1\end{array}$ \\
\hline 10.5 .2 & Wet insulation test & $\begin{array}{l}\text { Measure } R \text { at } 500 \mathrm{~V} \text { when the sample is wetted } \\
\text { by surfactant solution with resistivity } \\
<3500 \Omega \mathrm{cm} \text {. } \\
\text { Coolant present, no circulation required }\end{array}$ & $\begin{array}{l}\text { Receiver or module: } \\
\text { Coolant present, no circulation } \\
\text { Assemblies: } \\
\text { Max outlet temperature (MOT) } \\
\text { Use same flow rate from Test } 10.2 .2 .1\end{array}$ \\
\hline 10.6 .3 & Thermal cycling test & $\begin{array}{l}\text { All TC test options are from }-40^{\circ} \mathrm{C} \text { to } T_{\max } \text {. } \\
\text { Apply } 1.25^{*} \mathrm{I}_{\mathrm{sc}} \text { when } T>25^{\circ} \mathrm{C} \text { with cycle speed } \\
\text { of } 10 \text { electrical/thermal }\end{array}$ & $\begin{array}{l}\text { Exclude coolant from the receiver and } \\
\text { adjust the current injection to account } \\
\text { for the lower thermal mass }\end{array}$ \\
\hline 10.11.4 & Bypass/blocking diode thermal test & $\begin{array}{l}\text { At } 75^{\circ} \mathrm{C} \text { sample temperature, apply Isc through } \\
\text { the receiver for } 1 \mathrm{~h} \text {, then measure } \\
\text { bypass/blocking diode temperature. } \\
\text { Apply } 1.25^{*} \text { Isc for additional } 1 \mathrm{~h}\end{array}$ & $\begin{array}{l}\text { Test for receivers only: } \\
\text { Flow coolant. } \\
\text { Use same flow rate from Test 10.2.2. } \\
\text { Coolant temperature should be } \\
\text { adjusted to meet ensure that the diode } \\
\text { temperatures are met within the } \\
\text { existing standard, with particular } \\
\text { attention to the note regarding the } \\
\text { cooling of diodes. If MOT is higher than } \\
75^{\circ} \mathrm{C} \text {, then MOT should be used }\end{array}$ \\
\hline 10.14 .3 & Off-axis beam damage test & $\begin{array}{l}\text { Aim the light on suspect locations for at least } \\
15 \text { min when DNI }>800 \mathrm{~W} / \mathrm{m}^{2} \text {; or walk-off for } \\
3 \mathrm{~h}\end{array}$ & $\begin{array}{l}\text { Receiver, module, or assembly (design } \\
\text { dependent). } \\
\text { Loss of grid test: Coolant present, no } \\
\text { flow, } 3 \text { h walk-off or system proves it } \\
\text { can point away from the sun. } \\
\text { Coolant loss test (system points away } \\
\text { from the sun) or withstands } 3 \mathrm{~h} \\
\text { walk-off }\end{array}$ \\
\hline 10.15 .2 & UV conditioning test & $\begin{array}{l}\text { Expose to UV accumulation of } 50 \mathrm{kWh} / \mathrm{m}^{2} \text {. } \\
\text { Cooling system working }\end{array}$ & $\begin{array}{l}\text { Max outlet temperature (MOT) } \\
\text { Use same flow rate from Test 10.2.2.1 }\end{array}$ \\
\hline 10.16 .2 & Outdoor exposure test & $\begin{array}{l}\text { Expose to DNI accumulation of } 1000 \mathrm{kWh} / \mathrm{m}^{2} \\
\text { when DNI }>600 \mathrm{~W} / \mathrm{m}^{2} \text {. } \\
\text { Cooling system working }\end{array}$ & $\begin{array}{l}\text { Max outlet temperature (MOT) } \\
\text { Use same flow rate from Test 10.2.2.1 }\end{array}$ \\
\hline
\end{tabular}

\subsection{The thermal components}

To test the thermal component of a hybrid concentrator photovoltaic-thermal system, it is important to control the maximum temperature that the different materials can withstand, especially when considering the photovoltaic section, including the solar cells and soldering joints. This temperature control is performed by determining the maximum temperature of the fluid in

Table 2

Variations proposed to the EN-12975-2:2006 for hybrid photovoltaic-thermal systems.

\begin{tabular}{|c|c|c|}
\hline Test title & Test condition & Variation proposed for hybrid PV-thermal systems \\
\hline High temperature resistance & $\begin{array}{l}\text { Solar irradiance }>1000 \mathrm{~W} / \mathrm{m}^{2} \text { in the plane of the solar } \\
\text { collector. } \\
\text { Ambient temperature between } 20 \text { and } 40^{\circ} \mathrm{C} \text {. } \\
\text { Wind speed }<1 \mathrm{~m} / \mathrm{s} \text {. } \\
\text { No fluid in the absorber }\end{array}$ & $\begin{array}{l}\text { Define a maximum temperature in the absorber } \\
\text { according to the materials in the PV receiver; } \\
\text { or } \\
\text { Include fluid circulation }\end{array}$ \\
\hline Exposure & $\begin{array}{l}30 \text { days with a minimum irradiation of } 14 \mathrm{MJ} / \mathrm{m}^{2} \text { per } \\
\text { day. } \\
30 \mathrm{~h} \text { of at least } 850 \mathrm{~W} / \mathrm{m}^{2} \text { with ambient temperature } \\
>10^{\circ} \mathrm{C} \text {. } \\
\text { No fluid inside the absorber }\end{array}$ & Include fluid circulation \\
\hline External thermal shock & $\begin{array}{l}\text { Initial exposure for } 1 \mathrm{~h} \text { at high irradiance }\left(>850 \mathrm{~W} / \mathrm{m}^{2}\right) \text {, } \\
\text { with no fluid inside. } \\
\text { Water spray for } 15 \mathrm{~min}\end{array}$ & $\begin{array}{l}\text { Include fluid circulation; } \\
\text { or } \\
\text { Redefine the test according to CPV characteristics, } \\
\text { intermittent shadows (clouds) produce thermal shock }\end{array}$ \\
\hline Internal thermal shock & $\begin{array}{l}\text { Initial exposure for } 1 \mathrm{~h} \text { at high irradiance }\left(>850 \mathrm{~W} / \mathrm{m}^{2}\right) \text {, } \\
\text { with no fluid inside. } \\
\text { Fluid circulated till the absorber temperature drops } \\
\text { below } 50{ }^{\circ} \mathrm{C}\end{array}$ & $\begin{array}{l}\text { Include fluid circulation and redefine the test including } \\
\text { large fluid temperature changes below the maximum } \\
\text { temperature of the materials }\end{array}$ \\
\hline
\end{tabular}


tests such as the high temperature resistance and the internal thermal shock; or by re-defining the test considering the characteristics of the PV component. For example, CPV systems under exposure should always include fluid circulation. External thermal shock could be generated by intermittent shadows on the solar cells, which dramatically decreases the power output and, consequently, increases the thermal load. Table 2 shows the modifications proposed for tests of the thermal components of a hybrid system. These test variations could ideally be implemented in a new combined standard intended for hybrid systems based on the current standards for the single technologies which consider the critical issues arising from the integration of both technologies.

\subsection{Other issues arising from the CPV and thermal integration}

When working with combined systems, it is also important to identify new problems arising from the integration of the two separate technologies. This is especially critical when considering the durability of the system. For the same reasons as trackers in CPV need their own standard [1], in a hybrid CPV-T system it is also necessary to add extra tests to determine whether the system is able to deal with problems such as cooling system failures, or whether there is an adequate control system for the case when the thermal storage system has reached the maximum design temperature. The new hybrid system requires new strategies to control and protect the photovoltaic receiver against cooling system failures, and these failures should be anticipated and validated by appropriate test standards.

\section{Conclusion}

A thorough review of standards for CPV-T systems has been conducted in order to determine the suitability of the existing specified tests for actively-cooled CPV and hybrid CPV-T systems. The principal conclusion is that there is a lack of specifications for testing and qualifying actively-cooled CPV and hybrid CPV-T concentrators in the existing standards. This applies to both photovoltaic and thermal standards.

Photovoltaic standards IEEE 1513 and IEC 62108 have been reviewed, as well as solar thermal standards EN-12975-2:2006 and ISO 9806-2:1995. Variations for adapting the IEC 62108 tests and EN-12975-2:2006 tests for CPV-T systems have been proposed. These variations consider the main requirements arising from the solar photovoltaic and solar thermal technologies integration.

In conclusion, any new or hybrid technology that develops between the boundaries of two existing technologies should benefit from its own standards. These new standards should be based on existing standards, built around previous experience, and benefit from industry knowledge. This will lead to improved, reliable technology that benefits from consumer confidence through demonstrated manufacturing quality and reliability.

\section{References}

[1] Muñoz E, Vidal PG, Nofuentes G, Hontoria L, Perez-Higueras P, Terrados J Almonacid G, Aguilera J. CPV standarization: an overview. Renewable and Sustainable Energy Reviews 2010;14:518-23.

[2] IEEE 1513 standard. IEEE recommended practice for qualification of concentrator photovoltaic (PV) receiver sections and modules.

[3] EC 62108 standard. Concentrator photovoltaic (CPV) modules and assemblies-design qualification and type approval.

[4] European standard EN-12975-2:2006. Thermal solar systems and components. Solar collectors-Part 2: test methods, developed by AEN/CTN 94 committee; 2006.

[5] ISO 9806-2:1995. Test methods for solar collectors-Part 2: qualification test procedure. Geneva, Switzerland: International Organization for Standardization 1995. 